\title{
O conceito de moda e o seu papel nas relações de gênero
}

ARTIGO

\author{
The concept of fashion and their role \\ in the gender relations
}

Letícia Formoso Assunção

http://lattes.cnpq.br/0905336276702062

\section{Resumo}

Este trabalho apresenta um recorte da dissertação "Mademoiselle Chanel: um discurso entre a magia do glamour e a eloquência da solidão" defendida no Programa de Pós-Graduação em Letras da Universidade Católica de Pelotas no mês de dezembro de 2015. O presente artigo tem como objetivo principal discutir e analisar o conceito de moda e as implicações desta com as questões de gênero, evidenciando a participação das mulheres como designers e consumidoras deste sistema. Para fins de análise, utilizo fundamentos teóricos advindos das teorias de moda (principalmente CASTILHO, 2006; SIMMEL, 2008; BARTHES, 2005 e LIPOVETSKY, 2009) e dos estudos de gênero social (sobretudo FLAX, 1991; SCOTT, 1900 e BUTLER, 1998). A pesquisa realizada com base nestes pressupostos, permite concluir que o sistema de moda, por ser um produto dotado de valores simbólicos, além de cumprir com as questões tradicionais de adorno, pudor e proteção, age como um ato de significação profundamente cultural e social.

\section{Palavras-chave}

Moda. Significação. Cultura. Design. Gênero.

\section{Abstract}

This research aims to presents part of the dissertation "Mademoiselle Chanel: um discurso entre a magia do glamour e a eloquência da solidão" held at the Post-Graduate Program in Letters at the Catholic University of Pelotas on December 2015. The main objective of this article is to discuss and analyze the fashion concept and its implications with gender issues, highlighting the participation of women as designers and consumers of the system. For analysis, I adopt the theoretical basis arising from the fashion theories (mostly CASTILHO, 2006; SIMMEL, 2008; BARTHES, 2005 and LIPOVETSKY, 2009) and social Gender Studies (especially FLAX, 1991; SCOTT, 1900 and BUTLER, 1998). The research, based on these assumptions, shows that the fashion system, as a product endowed with symbolic values, beyond comply with such traditional issues of adornment, modesty and protection, he acts like an act of deep social and cultural signification.

\section{Keywords}

Fashion. Signification. Culture. Design. Gender.

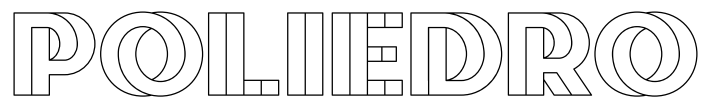




\section{Introdução}

Este artigo é um recorte da dissertação "Mademoiselle Chanel: um discurso entre a magia do glamour e a eloquência da solidão" defendida em dezembro de 2015 no Programa de Pós-Graduação em Letras da Universidade Católica de Pelotas. O objetivo principal desta pesquisa de Mestrado consiste em analisar no texto de Maria Adelaide Amaral (2004), a construção da (auto)biografia de "Mademoiselle Chanel" voltando atenção às questões de corpo, moda e gênero, com o fim de estabelecer de que forma o glamour e a solidão se presentificam na vida da protagonista.

A parte aqui apresentada pertence a uma contextualização inicial desta dissertação, cujo foco é discutir o conceito de moda e sua relação com as questões de gênero, temas que foram de fundamental importância para as análises e conclusões do trabalho. Neste primeiro capítulo do trabalho de mestrado, procuro mais especificamente abordar assuntos relativos à moda e sua inserção na academia e nos estudos teóricos, bem como a sua importância como um ato de significação social e uma expressão da subjetividade que revela uma visão de mundo. Além disso, neste texto reflito sobre a relevância do sistema de moda como uma ferramenta de status, de contracultura, e promotora de significação no que se refere a lugares e imagens de gênero.

\section{Conceitos e lugares da moda}

\footnotetext{
$<\quad$ A moda não é algo presente apenas nas roupas. A moda está no céu, nas ruas, a moda tem a ver com ideias, a forma como vivemos, o que está acontecendo. (Coco Chanel)
}

Tradicionalmente, as teorias em torno da moda carecem de prestígio, não possuindo o mesmo reconhecimento que, por exemplo, as artes visuais e a arquitetura. Este campo pode ser considerado de natureza ainda exploratória, em razão de seus pressupostos teóricos não estarem satisfatoriamente claros ou definidos. Entre o final do século XIX e o 
início do século XX, o tema obtém certo destaque nas reflexões de artistas e intelectuais empenhados em desvendar este fenômeno ${ }^{[1]}$. Porém, na entrada do século XX, a moda passa a ser estigmatizada, tendo seus estudos relegados ao ostracismo até os anos $1970^{[2]}$, ainda que a importância econômica e social do setor tenha crescido consideravelmente. Nos últimos anos do século XXI, esta condição se modifica em certo grau com um aumento das publicações acadêmicas sobre o assunto ${ }^{[3]}$. Para as/os pesquisadoras/es da área, a carência de estudos teóricos ou acadêmicos ainda representa uma lacuna, exigindo esforço no sentido de ampliar as possibilidades de compreensão do pensar/fazer moda (CASTILHO, 2006; CRANE, 2006; SVENDSEN, 2010).

Inscrita simultaneamente na história da arte e da humanidade, a moda ocupa um lugar singular, valendo a pena sublinhar sua importância. Estudá-la permite dar conta de mudanças sociais, da transformação de códigos culturais, da rapidez e da complexidade das trocas comerciais. A este respeito, o filósofo italiano Massimo Baldini (2006, p. 54) argumenta que a moda está tão intimamente ligada ao espírito humano que é como o seu reflexo. Com efeito, a moda indica posições sociais, explora e aponta posições sexuais, materializa subjetividades, se coloca em relação a instituições políticas ou ideológicas.

A teoria elaborada em 1905 pelo sociólogo alemão Georg Simmel $(2008)^{[4]}$, defende que a moda caracteriza-se por unir o gosto pela imitação e o gosto pela mudança, o conformismo e o individualismo, a aspiração a fundir-se no grupo social e o desejo de diferenciar-se dele, ainda

[1] A lista dos que realmente dedicam alguma atenção teórica à moda entre o final do século XIX e o início do século XX inclui Thorstein Veblen e Georg Simmel. Veblen, em sua obra The Theory of the Leisure Class (1899/1974), foca na diferenciação de classes estabelecidas pelo vestuário. Já Simmel trabalha no seu tratado Philosophie der Mode (1905/2008) com o vínculo entre moda e identidade.

[2] Roland Barthes e Gilles Lipovetsky se enquadram nos autores que escreveram sobre moda nesta época. Système de la mode, de Roland Barthes (1967/2009), trata de uma abordagem semiológica do tema e Lipovetsky publica em 1987 (2009) um dos primeiros ensaios críticos sobre a evolução da moda nos séculos XIX e XX em L'empire de l'éphémère.

[3] Nos últimos anos do século XXI há o trabalho da norte-americana Diana Crane (2000/2006), do norueguês Lars Svendsen (2004/2010) e das brasileiras Kathia Castilho (2004/2006) e Mara Rúbia Sant'Anna (2014) na formação dos primeiros polos de pesquisa em moda e ciências humanas. 
que por pequenos detalhes. Para o autor, a moda se manifesta a partir de um processo de imitação das elites sociais por parte de seus inferiores, desencadeando um movimento transitório. Este fenômeno denominado de "trickle down effect ${ }^{[5]}$ " é ampliado, posteriormente, com a noção de que as novidades podem vir também dos estratos mais baixos

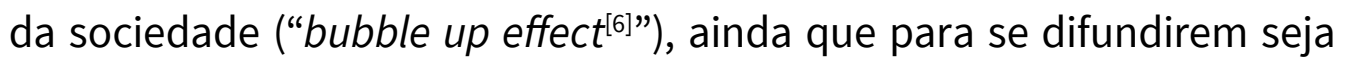
"necessário um exemplo social de grande destaque [...] de onde provenha um contínuo fluxo de imitação" (BALDINI, 2006, p. 65). A respeito deste processo de difusão "de baixo para cima", Crane (2006) acrescenta que fatores como a idade e o estilo de vida podem substituir, em certos casos, o status social como variáveis que transmitem prestígio à/ao inovadora/inovador de moda.

Como um produto sociocultural, a moda materializa-se e atualiza-se no processo desencadeado pelas escolhas - de trajes, adornos e acessórios - realizadas pelo sujeito. 0 adorno, o pudor e a proteção são entendidos, por grande parte dos teóricos de moda, como as motivações fundamentais da utilização de roupas pelos seres humanos. Entretanto, Castilho (2006) relata que a partir de estudos verificou-se que a necessidade de adornar-se, de enfeitar-se, está entre os anseios primeiros ${ }^{[7]}$. Independentemente de assumir função estética, de proteção, pudor ou magia, a indumentária ${ }^{[8]}$, compreendida como uma ocorrência universal fundada em todas as sociedades humanas, sempre serviu como uma forma de expressão, de comunicação. Existem, ainda hoje, sociedades humanas que desconhecem por completo a roupa, porém, nenhuma delas, por sua vez, ignora a arte de se adornar (CASTILHO, 2006).

Cumprida a sua função primeira - de adornar e embelezar o corpo - a moda e o próprio corpo constroem regimes de interações e de presença, desempenhando uma ampla variedade de funções comunicativas. Contudo, para Roland Barthes (2005), o vestuário, além de comu-

[5] Em português também conhecido como efeito gotejamento.

[6] Efeito ebulição.

[7] Segundo a autora, esta é uma necessidade básica mesmo dos primevas, que revestem seus corpos antes para o embelezamento do que para a proteção. 
nicativo, é também significativo, visto que significar quer dizer que os objetos não veiculam apenas informações (caso em que comunicariam), mas constituem também sistemas estruturais de signos de diferenças, de oposições e de contrastes. $O$ autor considera que

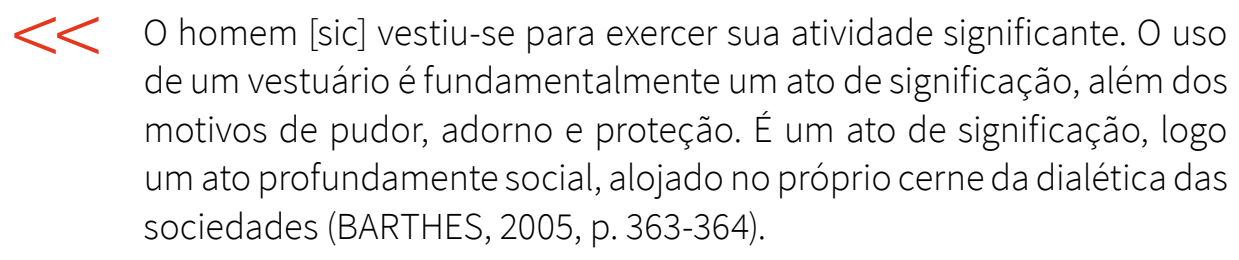

Diferentes pesquisadoras/es deram como certa a existência de uma linguagem do vestuário ${ }^{[9]}$ (BALDINI, 2006, p. 94). Sob esta perspectiva, a indumentária desempenha um papel singular na percepção de si e do outro na interação social, caracterizando-se como uma expressão constante da subjetividade. No interior das possibilidades humanas criadas para o fenômeno da comunicação e da significação, a moda pode ser entendida como a manifestação de um discurso, podendo ser lida como um texto[10], que, por sua vez, veicula um discurso. Na função de discursos não-verbais, as roupas compõem uma arquitetura têxtil em que, segundo Castilho (2006),

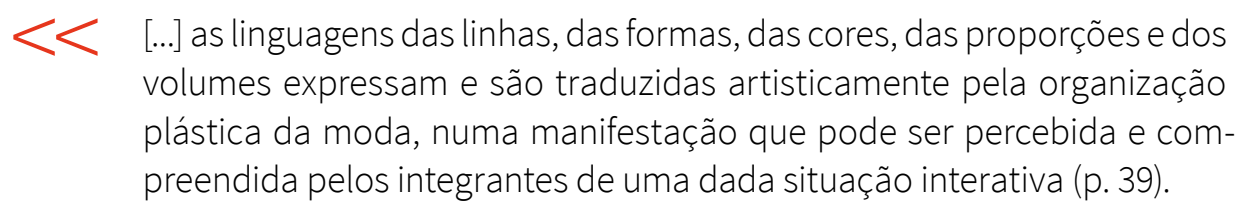

[9] Conjunto de peças de roupas e complementos que as acompanham. 0 vestuário possui usos diversos, podendo ser um elemento de moda, um traje popular, um figurino cênico, uma indumentária, etc. (CRANE, 2006, p. 21-22).

[10] Segundo Diana Crane (2006, p. 465), se considerarmos as roupas como textos, vemos que nas sociedades com classes bem definidas elas funcionam como textos "fechados", com um significado relativamente estável, pois as roupas mudam pouco. Nas sociedades atuais, mais fragmentárias e distantes de um processo de homogeneidade sociocultural, por outro lado, elas funcionam como textos "abertos", podendo adquirir novos significados a todo momento.

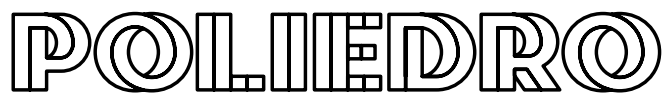


As escolhas operadas pelas pessoas evidenciam aspectos acerca de determinadas características próprias, permitindo atualizar suas posições ou revelar seus dados. Ao se visualizar um sujeito pode-se apreender, pelos modos de sua manifestação, particularidades como o tipo de papel que ele possui na sociedade, sua posição econômica, suas conjunções ou disjunções com valores sociais, seu caráter psicológico, sua visão de mundo, seus humores, etc. Ademais, por integrarem uma história localizada no tempo e no espaço, as roupas auxiliam na transmissão de valores de uma sociedade: "elas veiculam assim uma concepção ética e estética” (CASTILHO, 2006, p. 130).

Os seres humanos se consideram incorporados à sociedade também quando se revestem pelas características culturais, ou seja, assumem a uniformidade dos gestos, das regras e das construções vestimentares, as quais os permitem assimilar a sua natureza inserida em determinada cultura. Além desta postura reconhecida como contratual, Castilho (2006) relata que, de forma contrária, as pessoas podem assumir posições polêmicas em relação aos valores estabelecidos que garantem uma dada ordem social, bastando, para isso, incorporarem comportamentos que estejam em oposição às "normas". Desta maneira, os seus modos de parecer significam o seu ser e estar no mundo.

\section{A moda que "fala" sobre gêneros}

As questões de gênero surgem como um relevante tema, visto que este é compreendido por meio dos "[...] significados de masculino e de feminino e das consequências de ser atribuído a um ou a outro gênero dentro de práticas sociais concretas" (FLAX, 1991, p. 230). Os significados para o que é ser mulher e ser homem não estão ligados aos conceitos biológicos, ou seja, às características anatômicas e fisiológicas do sexo feminino e masculino, mas sim às construções socioculturais, às representações significativas relacionadas às formas pelas quais se reconhece e se distingue cada sexo e o que passa a ser definido como masculinidade e feminilidade em um determinado momento histórico. Assim, o gênero é pensado com respeito a diferenças sociais percebidas entre os sexos, conforme a cultura, a época, a idade, a raça e a classe social. 
Portadora de uma série de construções discursivas, a moda possibilita classificações recíprocas entre os sujeitos segundo diversos aspectos, entre os quais o sexo. Castilho (2006) levanta a hipótese de que o vestuário é sempre capaz de expressar visualmente a oposição entre os sexos, assinalando características do feminino e do masculino. Segundo a autora, as regras de categorias de trajes, diferentes para homens e mulheres, "são impostas a cada indivíduo em qualquer contexto social, desde os primeiros meses de vida até sua morte" (p. 110) e são permeadas por um caráter de extrema rigidez, em que o uso dos trajes previstos a cada sexo, expressa adequação perante o grupo social. Em acordo com este pensamento, Crane (2006) aponta:

\footnotetext{
$<<$ Sendo uma das mais evidentes marcas de status social e de gênero - útil portanto para manter ou subverter fronteiras simbólicas -, o vestuário constitui uma indicação de como as pessoas, em diferentes épocas, veem sua posição nas estruturas sociais e negociam as fronteiras de status (p. 21).
}

Apesar de serem processos socioculturais historicamente variáveis, as relações de gênero revelam ser (mais ou menos) relações de dominação (FLAX, 1991, p. 228). Há muito tempo presente e estabelecida nas civilizações ocidentais, a cultura patriarcal, em que o homem possui um poder maior do que a mulher, dá a impressão de ser parte da natureza humana, permitindo que sejam consideradas privilegiadas as qualidades e os significados associados ao masculino (SCOTT, 1990). A consequência da naturalização desta rígida estrutura social é o aprisionamento, por parte dos indivíduos, aos estereótipos, no intuito de se ajustarem aos conceitos pré-estabelecidos de papéis direcionados à mulher e ao homem, em que a primeira é caracterizada por fraqueza, passividade, emoção, delicadeza e gentileza, enquanto o segundo é compreendido como dotado de força, dominação, racionalidade, coragem, ousadia, agressividade.

Judith Butler (1998) coloca que gênero é "[...] a estilização repetida do corpo, um conjunto de atos repetidos dentro de um molde altamente rígido que se consolida ao longo do tempo para produzir a aparência de substância de um tipo 'natural' de ser" (p. 32, ênfase no original). A 
produção e reprodução de discursos pelos sujeitos em um contexto histórico, político e social, produz um sistema de representações e autorrepresentações sociais, expressas não só em comportamentos e padrões morais, mas também em modelos corpóreos e em normas vestimentares. Desta forma, a partir de um contrato implícito, homens e mulheres tendem a aceitar as regras de estruturas básicas referentes às formas de adornar-se e de vestir-se.

Tradicionalmente, os trajes e adornos significam de maneiras diversas quando são usados pelos diferentes sexos. As roupas são capazes de apresentar mensagens que se referem às maneiras pelas quais mulheres e homens consideram seus papéis de gênero, ou como se espera que elas/eles os percebam. Nas referências atreladas ao sexo feminino, por exemplo, a moda ocidental privilegia atualmente, sobretudo, a região dos ombros e braços, colo e seios, cintura, quadril. Nas associações feitas com o sexo masculino, por outro lado, destaca-se a importância que a moda confere aos ombros e braços, tórax, quadril e pernas (CASTILHO, 2006, p. 147).

Ao longo da história do vestuário, conforme explica Castilho (2006), é sempre o traje masculino o que menos sofre interferência em suas formas e proporções e o que mais se aproxima da realidade anatômica humana. O feminino, por sua vez, vem mostrando efetuar sobre a anatomia operações de mudanças de maior intensidade que enfatizam algumas regiões corpóreas específicas. Mediante o uso de diversos artifícios, a mulher modifica a sua visualização corpórea, anulando, dissimulando, ampliando ou engrandecendo certas partes do corpo $^{[11]}$. Ainda sobre a produção de características diversas no masculino e no feminino por parte da moda, a autora coloca que,

\title{
$<$ a vestimenta masculina sempre esteve relacionada à sua concepção social: [...] à guerra, à força, à possibilidade de sobrevivência, ao tra- balho e a todas subdivisões sociais que esse oferece e classifica em
}

\begin{abstract}
[11] Diversos casos na História da vestimenta podem ser citados para ilustrar esta afirmação, dentre eles: a deformação dos pés das chinesas, com o objetivo de garantir um bom casamento, pois a mulher não consegue caminhar e depende absolutamente de seu marido; as saias ocidentais do Barroco e Rococó, uma vez que a arquitetura dos castelos e o mobiliário devem ser modificados para que as mulheres possam ocupar e se locomover neste espaço, e o espartilho, o qual dificulta a circulação sanguínea da mulher, fazendo-a, muitas vezes, desmaiar, ressaltando a valorização da figura masculina vista como capaz de garantir a sobrevivência desta mulher (CASTILHO, 2006, p. 120).
\end{abstract}


termos de estabilidade de classes econômicas e sociais. No que diz respeito à decoração do corpo feminino, a busca é, de maneira geral, a de realçar, por meio do traje, a sensualidade, exibindo um jogo articulado entre o revelar e o velar, o mostrar e o ocultar, o evidenciar e o dissimular, as diferentes regiões do corpo, consideradas culturalmente sensuais ou eróticas (p. 183).

A diferenciação entre a indumentária feminina e a masculina se dá por volta de 1350 , junto ao nascimento do sistema da moda ${ }^{[12]}$. Este sistema, que possui como principal característica o seu caráter efêmero, começa a existir quando as sociedades passam a aderir à mudança contínua de vestuário, pois "não há sistema de moda senão quando o gosto pelas novidades se torna um princípio constante e regular" (LIPOVETSKY, 2009, p. 30). Mesmo que certas civilizações tenham sido menos conservadoras do que outras, em razão dos seus estilos muito duradouros ${ }^{[13]}$, pode-se dizer que

\footnotetext{
$<$ A moda no sentido estrito quase não aparece antes da metade do século XIV. Data que se impõe, em primeiro lugar, essencialmente em razão do aparecimento de um tipo de vestuário radicalmente novo, nitidamente diferenciado segundo os sexos: curto e ajustado para o homem, longo e justo para a mulher. Revolução do vestuário que lançou as bases do trajar moderno (LIPOVETSKY, 2009, p. 31)
}

O nascimento da moda no Ocidente coincide com a promoção do masculino como "padrão da aparência", revelando o lugar preponderante dos homens na esfera do vestuário. No século XVII, as vestimentas femininas são ainda muito mais sóbrias e sofrem menos transformações que as masculinas. Certos trajes, quando utilizados pelos homens, assumem significados específicos, como a glória na hierarquia militar, civil ou religiosa. "No conjunto, a indumentária masculina conferia aos

[12] Afirma-se em geral que a moda no vestuário tem suas origens no fim do período medieval, possivelmente no início do Renascimento, em conexão com a expansão do capitalismo mercantil (SVENDSEN, 2010, p. 22).

[13] Conforme Svendsen (2010), não se pode falar de moda na Antiguidade grega e romana, por exemplo, porque nesta época não há autonomia estética individual na escolha das roupas. O vestuário europeu muda relativamente pouco da era romana até o século XIV. Embora tenham variações nos materiais e nos detalhes das roupas, neste período, para todos os efeitos a sua forma permanece inalterada.

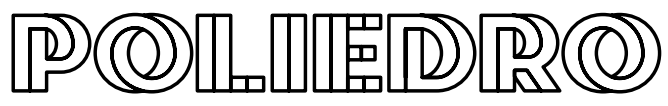


homens o poder, a grandeza, a riqueza e a dignidade no contexto de uma determinada coletividade" (CASTILHO, 2006, p. 113).

É apenas no século XVIII que se efetua a oscilação histórica da moda que permanece até hoje, em que os caprichos, as extravagâncias, os refinamentos tornaram-se mais característicos do feminino que do masculino (LIPOVETSKY, 2009). O século XIX sistematiza e institucionaliza esta preeminência feminina na ordem da aparência, da moda e do luxo. $O$ homem agora se veste sobriamente, visto que as suas atenções estavam voltadas para o cultivo da individualidade através do trabalho, do saber através do interesse pelas ciências e do gosto pelas artes. Já a mulher passa a ser responsável por evidenciar a riqueza e o poder econômico de seu marido através do vestuário, por meio de objetos de joalheria e trajes preciosos realizados pela alta-costura ${ }^{[14]}$.

As roupas da moda para as mulheres do século XIX possuem elementos de controle social, pois exemplificam a concepção dominante e restritiva dos papéis femininos da época. A natureza ornamental e nada prática do estilo de roupas das mulheres de classe alta, por exemplo, são reflexo do seu papel ideal de esposa e mãe, o qual não permite que trabalhem dentro ou fora de casa (CRANE, 2006). O modelo da mulher "dona de casa", destinada exclusivamente às tarefas domésticas, de esposa e de mãe, vai de encontro ao seu papel de protagonista do consumo e alvo primeiro da oferta mercantil. Lipovetsky (2005) corrobora esta afirmação explicando que, a partir do século XIX, é a mulher que "dirige o consumo, perde-se nas delícias da compra, passa horas olhando vitrines, informa-se das novidades do comércio, vê-se tomada pela necessidade incoercível de consumir nos grandes magazines" (p. 72).

Estes fatores enraízam-se nos sistemas de valores e representações relativos à desigualdade de gêneros, nos papéis conferidos às mulheres

[14] A alta-costura (haute couture) nasce em Paris no final do século XIX, caracterizando-se por ser uma confecção original centrada no luxo, no fazer à mão e sob medida. Em 1925, as suas vendas representam 15\% das exportações francesas globais e ocupam a segunda posição no comércio exterior. Em 1953, a alta-costura parisiense produz 90 mil peças (LIPÓVETSKY, 2005, p. 44). Este tipo de criação em escala artesanal opõe-se à produção em série e barata, chamada "ready-to-wear" (pronto para usar ou prêt-à-porter). À integração do "ready-to-wear" ao sistema da moda força as casas de alta-costura a adotarem um novo sistema como forma de sobrevivência. Assim, surge o prêt-à-porter de luxo, a partir de uma ideia de produção intermediária, oferecendo peças de qualidade elevada a preços mais baixos se comparados aos da alta-costura. Os valores das roupas deixam de ser exorbitantes, pois as peças não são mais exclusivas e o trabalho não é realizado manualmente. 
e aos homens. Neste viés, ao longo da história, as mulheres vêm sendo associadas sistematicamente ao espaço privado e ao decorativo e os homens ao espaço público, à dominação política e econômica. Assim, as elas passam a ter a "obrigação de aparecer como o mais belo ornamento do homem, [...] não podendo chegar à felicidade senão no amor e no devotamento familiar" (LIPOVETSKY, 2005, p. 71). Somente no final do século XX é que começa a existir uma tentativa de reorganização estética mediante princípios baseados na igualdade de gêneros.

Embora os ideais hegemônicos de comportamento e aparência ainda permaneçam bastante diferentes para cada um dos gêneros, atualmente as noções fixas de identidade correspondentes às mulheres e homens e a intolerância à diversidade sexual entram em debate, iniciando um processo de transformação, de unificação. Como reflexo destes acontecimentos, a moda, por sua vez, começa a assumir um papel ambíguo, tendo em vista que ela é produto do social e sedimenta e reafirma o que é considerado padrão. Alguns artigos do vestuário, lentamente, começam a ser usados irrestritamente por homens e mulheres, subvertendo as normas estéticas. Neste sentido, algumas marcas de roupas que vestem ambos os sexos fazendo uso das mesmas peças, estão crescendo em número e visibilidade no mercado ${ }^{[15]}$, inaugurando uma moda unissex que aponta para uma possível desconstrução dos papéis de gênero.

\section{Moda e mulheres, mulheres na moda}

As diferenças de gênero não são cruciais somente na definição dos padrões estéticos das roupas e das atribuições no consumo de moda, mas são igualmente determinantes na demarcação dos papéis na produção de artigos de moda. A assimetria dos lugares das mulheres e dos homens ocorre também na profissão de designer de moda, compreendida como a atividade que tem como objetivo a criação de indumentárias assinadas, ou seja, trajes, adornos e acessórios que expressem os gostos e preferências da/o profissional responsável. Sobre a desigualdade de gênero no mercado de trabalho, Lipovetsky (2000) explica que,

[15] As marcas Lowie, Commes des Garçons e Yohji Yamamoto são algumas representantes da moda que acaba com o limite entre roupa para homem e roupa para mulher, popularmente conhecida como Agender.

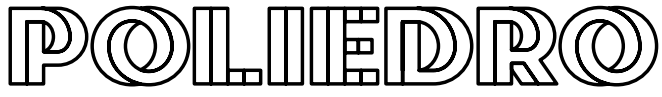




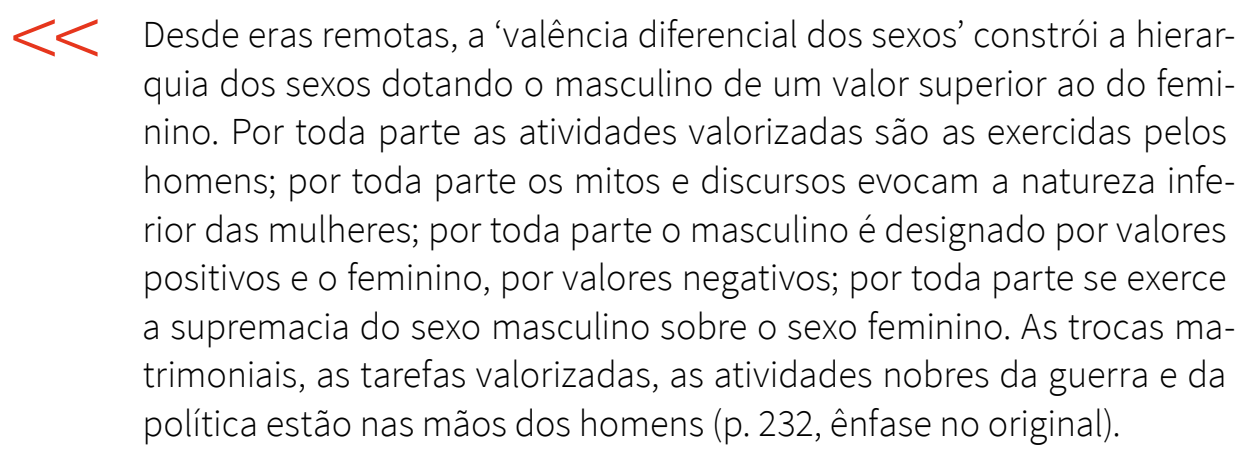

Por certo, é inegável que as mulheres já não são exclusivamente destinadas à esfera privada e que o trabalho feminino adquiriu uma legitimidade social. Todavia, é igualmente verdade que sua condição nem sempre é semelhante à do trabalho masculino. Culturalmente, as atividades das mulheres ainda estão relacionadas ao trabalho doméstico e familiar, remetendo ao binômio "homem-provedor" e "mulher-cuidadora". Sob esta perspectiva, Lipovetsky (2000) afirma que "por trás das aparências de permutabilidade dos papéis, reorganizam-se inscrições sociais diferenciais de cada sexo diante do trabalho e da família" (p. 241). Além disso, o autor expõe que,

\footnotetext{
$<<$ A despeito de profundas mudanças, é preciso constatar que o estatuto do trabalho feminino segue não sendo análogo ao dos homens. E se a mulher ganhou o direito ao trabalho externo, não deixa por isso de continuar reservada às funções domésticas. Todas as pesquisas de que dispomos mostram que são as mulheres que continuam a assumir a maior parte da responsabilidade na educação dos filhos e nas tarefas domésticas (LIPOVETSKY, 2005, p. 74).
}

Mesmo em trabalhos habitualmente considerados femininos pela sociedade como, por exemplo, o ato de coser e de cozinhar, a ascensão a cargos mais elevados, de maior prestígio, é dificultada e, algumas vezes, vetada às mulheres. Historicamente, costurar e preparar comidas são funções destinadas às mulheres; contudo, isso ocorre quando os trabalhos de costura e cozinha são considerados mais simples, menos qualificados e com menores salários. Este cenário inverte-se na medi-

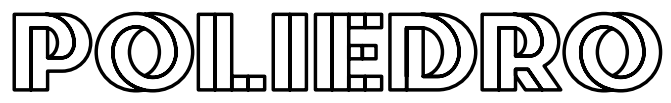


da em que as funções passam a ser especializadas, reconhecidas como ofício e possuidoras de maiores remunerações. "Há muito mais chefs de cozinha homens que mulheres, assim como há muito mais estilistas de alta-costura homens que mulheres" (THOME, 2010, p. 833).

Na moda, o poder conferido à mulher envolve o consumo e os usos, enquanto o domínio masculino atua nos trabalhos de elaboração e gerência dos produtos do vestuário. Em uma lista elaborada pela revista Time ${ }^{[16]}$, a qual exibe os mais influentes ícones de moda desde $1923^{[17]}$, é possível perceber que, dos 45 designers de moda eleitos, apenas 10 são mulheres. Do mesmo modo, na obra de Palomo-Lovinski (2010) que aponta os estilistas mais influentes do mundo, dentre os 50 criadores de moda apresentados, somente 14 são do sexo feminino, conforme pode ser observado no quadro a seguir:

\section{MAIORES DESIGNERS DE MODA}

\begin{tabular}{|c|c|c|}
\hline$\widehat{A}$ Paul Poiret & $\widehat{o}$ Claude Montana & $\widehat{O}$ André Courrèges \\
\hline$\widehat{o}$ Karl Lagerfeld & $\hat{\jmath}$ Jean P. Gaultier & $\hat{o}$ Thierry Mugler \\
\hline$ð$ Ralph Lauren & o Ann Demeulemeester & $\widehat{~ N i c o l a s ~ G h e s q u i e ̀ r e ~}$ \\
\hline$\widehat{o}$ Calvin Klein & $\hat{o}$ Marc Jacobs & q Vivienne Westwood \\
\hline$\lesssim$ Tom Ford & q Stella McCartney & o Jil Sander \\
\hline$\widehat{\jmath}$ Isaac Mizrahi & $\widehat{\partial}$ Mariano Fortuny & $\hat{\partial}$ Gianni Versace \\
\hline q Coco Chanel & q Madeleine Vionnet & o Katharine Hamnett \\
\hline$\widehat{\partial}$ Adrian & $\widehat{~ C r i s t o ́ b a l ~ B a l e n c i a g a ~}$ & $\widehat{\partial}$ Helmut Lang \\
\hline$\partial$ Christian Dior & q Madame Grès & ô John Galliano \\
\hline q Claire McCardell & $\widehat{\jmath}$ Issey Miyake & $\widehat{o}$ Narciso Rodriguez \\
\hline
\end{tabular}

[16] Time é uma revista de notícias publicada nos Estados Unidos, apresentando também uma edição europeia (Time Europe), uma edição asiática (Time Asia) e uma edição canadense (Time Canada). Segundo observadores da imprensa mundial, a Time é hoje a revista semanal de maior circulação no planeta. Disponível em <http://time.com>. Acesso em jul. de 2016. 


\section{MAIORES DESIGNERS DE MODA}

\begin{tabular}{|c|c|c|}
\hline$\partial^{\lambda}$ Halston & đ̂Yohji Yamamoto & † Elsa Schiaparelli \\
\hline q Mary Quant & ふૈ Romeo Gigli & q Rei Kawakubo \\
\hline$\lesssim$ Giorgio Armani & $\widehat{\partial}$ Christian Lacroix & $\lesssim$ Martin Margiela \\
\hline ¿ Yves S. Laurent & $\widehat{O}$ Dries Van Noten & $\partial^{\lambda}$ Alexander McQueen \\
\hline$\lesssim$ Azzedine Alaia & $\widehat{~ F r a n c i s c o ~ C o s t a ~}$ & ○̂ Viktor \& Rolf \\
\hline q Donna Karan & $\widehat{o}$ Pierre Cardin & $\widehat{\partial}$ Hussein Chalayan \\
\hline + Miuccia Prada & $\widehat{o}$ Rudi Gernreich & * \\
\hline
\end{tabular}

Quadro 1: Designers de moda mais influentes do mundo. Baseado em Palomo-Lovinski, 2010. * Neste quadro, assim como na obra "Os estilistas de moda mais influentes do mundo" (2010), os nomes não estão posicionados de acordo com a relevância da/o criadora/criador para a indústria da moda, mas conforme os seguimentos e estilos estéticos.

Dados como este comprovam que a clivagem das orientações em função do sexo ainda é visível em diversas áreas, mesmo que nenhuma profissão possa mais ser considerada exclusivamente masculina. No âmbito da moda, a ação de costurar é atribuída às mulheres somente quando cumpre a função de atividade natural, referente à esfera privada ou, no máximo, a pequenos negócios, não gerando status e poder. No instante em que atinge este estágio, passa a ser admitida como uma profissão masculina. Efetivamente, as dificuldades encontradas pelas mulheres para se colocar no mercado de trabalho e ascender na carreira - também nas consideradas "atividades femininas" - podem ser entendidas como a máxima expressão das relações de poder entre os gêneros, demonstrando que a progressão do sexo feminino aos escalões hierárquicos do poder está apenas no início.

\section{Conclusão}

Após a contextualização, problematização e análise realizada neste artigo, é possível inferir que a moda pode ser entendida como um ato de significação profundamente social e cultural, indo muito além das ques- 
tões tradicionais de proteção, adorno e pudor. Entende-se que a moda é, portanto, um ato social, um sistema de significados que expressa a subjetividade humana e atua como um discurso não-verbal, expressando vontades, necessidades, desejos e visões de mundo. Por fim, pode-se apreender que a moda é uma concepção ética, estética e, algumas vezes, um ato de rebeldia ao status quo como uma ferramenta de contracultura, em oposição às "normas" socialmente instituídas.

Neste sentido, conclui-se que, ao longo dos anos, o sistema de moda afirmou um modelo dicotômico no que diz respeito aos espaços percebidos como próprios ao masculino e ao feminino. No entanto, este sistema permitiu, no decorrer do tempo, fissuras nesta dicotomia. Por dentro deste modelo estável normativo surge um espectro de outras possibilidades e lugares sociais, ou seja, o ser social contemporâneo vem permitindo a desestruturação da lógica binária na moda, a qual passa a possuir um papel fundamental na transformação social.

\section{Referências}

AMARAL, Maria Adelaide. Mademoiselle

Chanel. São Paulo: Globo, 2004.

BALDINI, Massimo. A invenção da moda: as teorias, os estilistas, a história. Tradução de Sandra Escobar. Lisboa: Edições 70, 2006.

BARTHES, Roland. (1995). Inéditos, vol. 3: imagem e moda. Tradução de Ivone Castilho Benedetti. São Paulo: Martins Fontes, 2005.

(1967). Sistema da moda. Tradução de Ivone

Castilho Benedetti. São Paulo: Editora Martins Fontes, 2009.

BUTLER, Judith. Fundamentos contingentes: o feminismo e a questão do pós-modernismo. Tradução de Pedro Maia Soares. Cadernos Pagu, n.11, p. 11-42, 1998.

CASTILHO, Kathia. Moda e linguagem. São

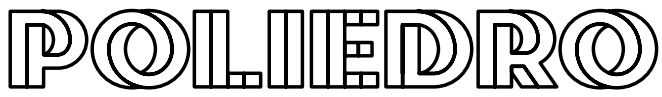


Paulo: Anhembi Morumbi, 2006.

CRANE, Diana. (2000). A moda e seu papel social: classe, gênero e identidade das roupas. Tradução Cristiana Coimbra. São Paulo: SENAC São Paulo, 2006.

FLAX, Jane. Pós-modernismo e as relações de gênero na teoria feminista. Tradução de Carlos A. de. C. Moreno. In: HOLLANDA, Heloísa Buarque de (org.). Pós-modernismo e política. Rio de Janeiro: Rocco, 1991. p. 217- 250.

LIPOVETSKY, Gilles. A terceira mulher: permanência e revolução do feminino. Tradução de Maria Lúcia Machado. São Paulo: Companhia das Letras, 2000. . (1987). O Império do Efêmero: a moda e seu destino nas sociedades modernas. Tradução de Maria Lúcia Machado. São Paulo: Companhia das Letras, 2009.

LIPOVETSKY, Gilles; ROUX, Elyette. O luxo eterno: da idade do sagrado ao tempo das marcas. Tradução de Maria Lúcia Machado. São Paulo: Companhia das Letras, 2005.

PALOMO-LOVINSKY, Noel. Estilistas de moda mais influentes do mundo: a história e a influência dos eternos ícones da moda. Tradução de Rodrigo Popotic. São Paulo: Girassol, 2010.

SANT'ANNA, Mara Rúbia. Sociedade, imagem e consumo.

São Paulo: Estação das Letras e Cores, 2014.

SCOTT, Joan. Gênero: uma categoria útil de análise histórica. Tradução de Christine Rufino Dabat e Maria Betânia Ávila.

Educação e Realidade, v.16, n. 2, p. 5-22, jul./dez. 1990. 
SIMMEL, Georg. (1905) Filosofia da moda e outros escritos. Tradução de Artur Morão. Lisboa: Edições Texto e Grafia Ltda., 2008.

SVENDSEN, Lars. (2004). Moda: uma filosofia. Tradução de Maria Luiza X de A. Borges. Rio de Janeiro: Zahar, 2010.

THOME, Candy Florêncio. A licença-paternidade como desdobramento da igualdade de gênero - um estudo comparativo entre o Brasil e a Espanha. Revista LTr, v. 74, n. 07, jul. 2010, p. 832-838.

VEBLEN, Thorstein. (1899). A teoria da classe ociosa.

Tradução de Olívia Krahenbuhl. São Paulo: Ática, 1974. 